\title{
Left ventricular pseudoaneurysm following undiagnosed myocardial infarction: the curious case of the woman with three ventricles
}

\author{
Majd Ibrahim, Darrel C Gumm
}

University of Illinois College of Medicine at Peoria/OSF Saint Francis Medical Centre, Peoria, Illinois, USA

\section{Correspondence to} Dr Majd Ibrahim, ibrahimm@uic.edu

Accepted 22 June 2015
CrossMark

To cite: Ibrahim $M$, Gumm DC. BMJ Case Rep Published online: [please include Day Month Year] doi:10.1136/bcr-2015211597

\section{DESCRIPTION}

A 66-year-old woman with a medical history of hypertension and tobacco use presented with progressive exertional dyspnoea over the past 6 months. She reported being treated with antibiotics earlier for bronchitis. She described dyspnoea on exertion, which improved when supine. Physical examination was notable for tachycardia, clear lung sounds and a new high-pitched III/VI systolic murmur best heard at the apex and radiating to the axilla. ECG showed a possible old inferior infarct (figure 1). Chest X-ray revealed a new retro-cardiac mass. Transthoracic echocardiogram was suspicious for a large posterobasal pseudoaneurysm with two rupture sites at the inferior base, and a preserved ejection fraction. The patient was urgently referred for cardiac catheterisation and ventriculogram to further identify her pseudoaneurysm and possible concomitant coronary artery disease.

The patient's cardiac catheterisation with left ventriculogram showed a lateral wall motion abnormality and a large pseudoaneurysm (figures 2 and 3 , videos 1 and 2). She was also found to have an occluded left circumflex artery and significant stenosis in the left anterior descending (LAD) artery. She was referred for surgery and underwent

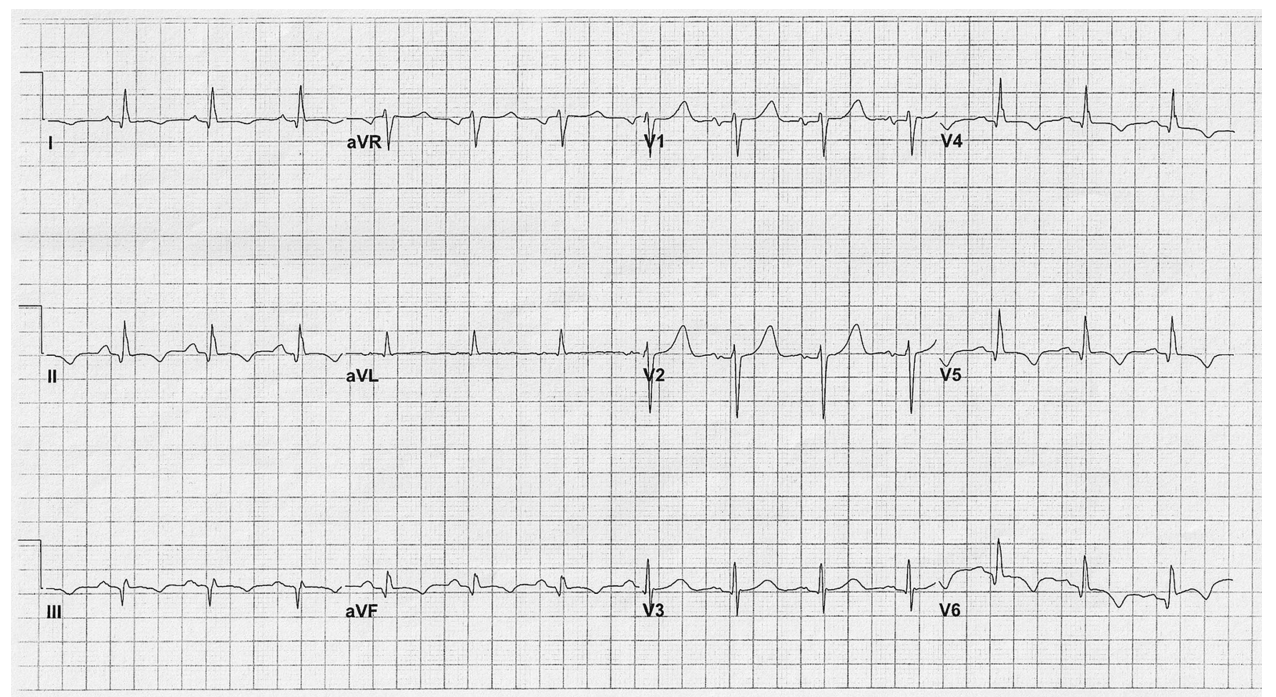

Figure 1 ECG showing sinus rhythm, old inferior infarct, and conduction delay in the terminal part of QRS complexes in leads II and aVF.

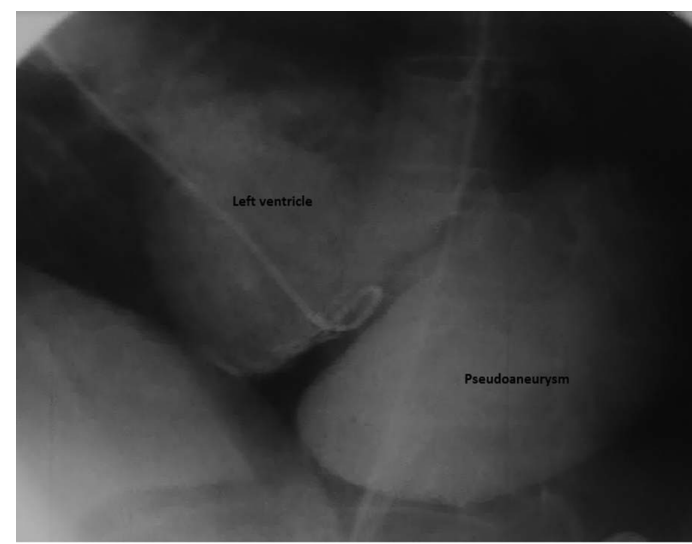

Figure 2 Left ventriculogram obtained in the left anterior oblique (LAO) projection showing a large pseudoaneurysm originating from the posterior wall.

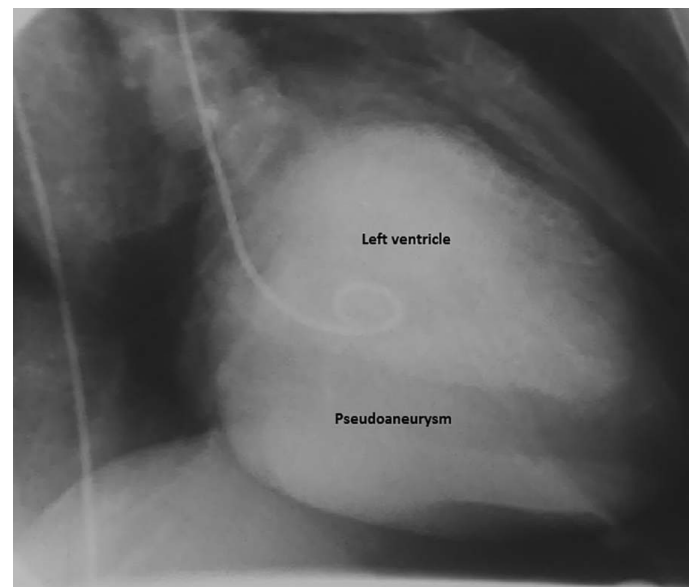

Figure 3 Left ventriculogram obtained in the right anterior oblique (RAO) projection showing contrast media permeating the pericardium from the ventricle. 


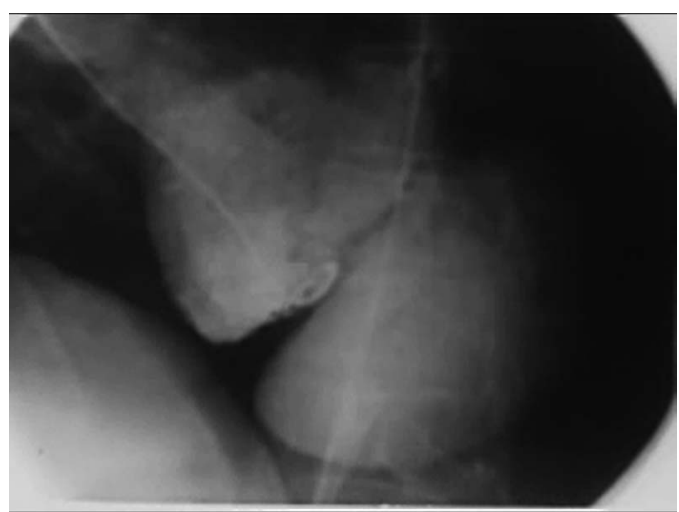

Video 1 Left ventriculogram obtained in the left anterior oblique projection showing a large pseudoaneurysm originating from the posterior wall.

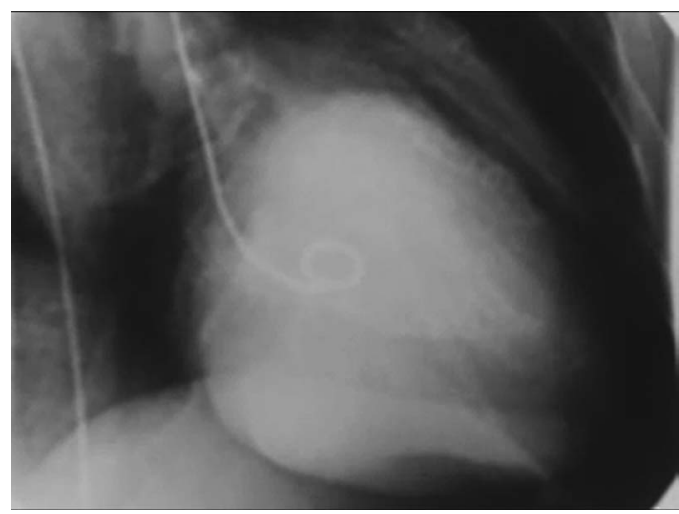

Video 2 Left ventriculogram obtained in the right anterior oblique projection showing contrast media permeating the pericardium from the ventricle.

resection of the pseudoaneurysm, patch repair and coronary artery bypass grafting to the LAD. The surgical report described two $1 \mathrm{~cm}$ openings, each on the posterolateral wall midway between the base and the apex.

Follow-up stress tests at 1 and 3 years postsurgery were negative for ischaemia. Despite the high mortality rates of left ventricular pseudoaneurysm, our patient is doing well 24 years postoperatively, at 90 years of age.

Contributors MI collected all data and wrote the manuscript. DCG revised and edited the manuscript.

Competing interests None declared.

Patient consent Obtained.

Provenance and peer review Not commissioned; externally peer reviewed.

\section{Learning points}

Left ventricular (LV) pseudoaneurysm results from a cardiac-free wall rupture contained by adherent pericardium or scar tissue without any myocardium or endocardium. ${ }^{1}$ An inflammatory reaction of the posterior pericardium may result in pericardial adhesions and the formation of a posterior LV pseudoaneurysm rather than cardiac tamponade. ${ }^{2}$

- Myocardial infarction accounts for most LV pseudoaneurysms with inferior infarctions accounting for twice as many cases as anterior infarctions. ${ }^{2}$ Other aetiologies include surgery, trauma and endocarditis. ${ }^{1}$

- High clinical suspicion is crucial for early diagnosis and surgical treatment, which is the treatment of choice. An untreated pseudoaneurysm has a $30-45 \%$ risk of rupture. Despite surgical treatment, the mortality rate has been reported to be as high as $23 \%$ (which is getting lower with newer techniques) compared to medical therapy at $48 \%{ }^{2}$

- Most symptomatic patients will report symptoms of heart failure, dyspnoea or chest pain; however, $10 \%$ of patients can be asymptomatic. ${ }^{2}$ Classic physical examination findings include to-and-fro murmur produced by blood flowing in and out of the pseudoaneurysm. This murmur is similar to a mitral regurgitation murmur and cannot be easily distinguished. Almost one-third of patients might have no detectable murmur.

- The ECG changes are usually non-specific. The ECG may show slow conduction in the leads adjacent to the area of pseudoaneurysm or persistent ST segment elevation. ${ }^{1}$

- Cardiac catheterisation with left ventriculogram is the gold standard and is useful in outlining any concurrent coronary lesion in preparation for surgery. A pseudoaneurysm will typically have a narrow neck leading to a saccular aneurysm, with a ratio of the breach in the wall to the maximal diameter of the pseudoaneurysm of $50 \%{ }^{3}$

- Transthoracic echocardiography is an acceptable starting test in patients suspected of having a pseudoaneurysm. Enhanced cardiac CT or MRI has been increasingly used as non-invasive diagnostic measures.

\section{REFERENCES}

1 Bekkers SC, Borghans RA, Cheriex EC. Ventricular pseudoaneurysm after subacute myocardial infarction. Int J Cardiovasc Imaging 2006;22:791-5.

2 Frances C, Romero A, Grady D. Left ventricular pseudoaneurysm. J Am Coll Cardiol 1998;32:557-61.

3 Hulten EA, Blankstein R. Pseudoaneurysms of the heart. Circulation 2012;125:1920-5.

Copyright 2015 BMJ Publishing Group. All rights reserved. For permission to reuse any of this content visit

http://group.bmj.com/group/rights-licensing/permissions.

BMJ Case Report Fellows may re-use this article for personal use and teaching without any further permission.

Become a Fellow of BMJ Case Reports today and you can:

- Submit as many cases as you like

- Enjoy fast sympathetic peer review and rapid publication of accepted articles

- Access all the published articles

- Re-use any of the published material for personal use and teaching without further permission

For information on Institutional Fellowships contact consortiasales@bmjgroup.com

Visit casereports.bmj.com for more articles like this and to become a Fellow 